Western University

Scholarship@Western

Education Publications

Education Faculty

2014

\title{
The Logogenesis of Writing to Learn: A Systemic Functional Perspective.
}

Perry Klein

Western University, pklein@uwo.ca

Len Unsworth

Follow this and additional works at: https://ir.lib.uwo.ca/edupub

Part of the Language and Literacy Education Commons, and the Linguistics Commons

Citation of this paper:

Klein, P. D., \& Unsworth, L. (2014). The logogenesis of writing to learn: A systemic functional perspective. Linguistics and Education, 26, 1-17. 
The Logogenesis of Writing to Learn:

A Systemic Functional Perspective

Klein, P. D., \& Unsworth, L. (2014). The logogenesis of writing to learn: A systemic functional perspective. Linguistics and Education, 26, 1-17. 


\begin{abstract}
Writing to learn has become an important practice in science education. How is scientific knowledge constructed during writing? To investigate this question, we examined the process through which four university students constructed written explanations of either projectile motion or buoyancy. The analysis, informed by systemic functional linguistics, focused on the mapping of semantic elements to grammatical choices, and the way in which this mapping unfolded throughout the course of each text. The texts began largely congruently; grammar mapped closely to experience. Gradually, each text shifted toward greater use of grammatical metaphor. Nominalization allowed propositions and sequences of events to serve as participants in complex causal and epistemic relationships. Students' texts showed several properties of professional scientific texts: transcategorization, compaction, and logicality; however, professional science texts instantiate these properties synoptically and systemically, whereas student texts exemplify them dynamically and instantially.
\end{abstract}

Keywords: Writing to learn; semantics; syntax; grammatical metaphor; logogenesis; nominalization. 


\subsection{Introduction.}

\subsection{Writing to Learn.}

Writing has long been considered a vehicle for thinking and learning (Donald, 2001; Galbraith, 2009; Goody \& Watt, 1963; Oatley \& Djikic, 2008; Ong, 1982). The effects of writing on learning have been of particular interest in education (Emig, 1977; Klein, 1999; Nückles, Hübner \& Renkl, 2009). "Writing to learn" refers to a set of educational practices in which students engage in a writing activity for the purpose of coming to better understand content or disciplinary modes of reasoning. Writing to learn takes a variety of forms (Klein \& Yu, 2013). In one common type of activity, a student has an educational experience such as conducting a science experiment, and then writes a journal entry to interpret it (also called a "learning log" or “learning protocol;” e.g., Bangert-Drowns, Hurley, \& Wilkinson, 2004; Drabick, Weisberg, Paul, \& Bubier, 2007; Nückles et al., 2009). The purpose of the learning log is primarily to promote learning through reflective thinking; consistent with this, the principal readership is the writer himself or herself and the teacher. The writing is typically elicited through a brief thoughprovoking prompt; it is informal; it is typically completed in a single session resulting in a single draft of the text; it is typically completed individually; and it is about one page in length.

Previous research shows that writing usually contributes significantly to learning (Bangert-Drowns et al., 2004; Drabick et al., 2007; Klein, Piacente-Cimini \& Williams, 2007). Science education has been a particularly active venue for the investigation of the role of writing in learning, with promising results (Bangert-Drowns et al, 2004; Gunel, Hand \& McDermott, 2009; Wallace, Hand \& Prain, 2004). However, the effects of writing on learning are variable: In some tasks, most students show evidence of learning, while in others they do not; and within tasks, individual students similarly differ in learning outcomes (e.g., Bangert-Drowns et al., 
2004; Klein, 2004; Rivard, 2004). This variability invites the question, how, that is, through what process, do students use writing to learn? This paper addresses the question of process in terms of the way in which language functions to construe meaning. The time frame of interest in this paper is logogenesis, that is, the unfolding of meaning throughout a given piece of discourse, in this instance, a students' creation of a specific text (Halliday, 1998b, p. 88).

\subsection{Systemic Functional Linguistic Research on Science Text.}

Extensive research on the linguistics of scientific text has been carried out in systemic functional linguistics (hereafter, SFL; Banks, 2005; Halliday, 1997, 1998a, 1998b, 1999; Halliday \& Matthiessen, 1999; Kopple, 2002; Martin, 2011). The logogenesis of scientific text has been contrasted with the construal of experience in informal speech (Halliday, 1998b; Martin, 2011). "Construal" refers to the way in which elements of experience or semantic elements (e.g., participants, processes, attributes) are mapped onto grammatical choices (e.g., nouns, verbs, adjectives). Everyday language is thought to map experience to grammar in a way that is relatively congruent (See Table 1). For example:

1a. The cart rolled quickly along the floor, 1b. and then it hit the wall.

The unit of experience in a congruent text is the event; semantically, this is referred to as a figure, which is realized congruently as a clause. The central element of a figure is a change in experience, or process, realized as verb, e.g., rolled. Persons or concrete objects comprise participants in these processes, congruently realized as nouns or pronouns, e.g., cart. Processes occur in some circumstance, frequently realized as a prepositional phrase, e.g., along the floor; and they may occur in some specified manner, frequently realized as an adverb, e.g., quickly. 
Two or more events comprise a sequence; these are connected by a relator, realized as conjunction (e.g., and) linking two clauses.

Consequently, congruent discourse presents a dynamic construal of experience, in the sense that each clause focuses on a change in experience. Congruent mapping is considered to be primary, in the sense that it is more characteristic of early childhood speech than later childhood speech (Painter, 1999); it is more characteristic of texts that students read and write in the earlier stages of education, than those that they write in the later stages of education (Christie \& Derewianka, 2008); it is more characteristic of conversational speech than academic writing (Biber \& Vásquez, 2008); and within the discipline of science, it is more characteristic of historically earlier texts than later texts (Kopple, 2002).

Professional scientific text reconstrues experience in ways that have been extensively documented in previous literature (Banks, 2005; Halliday, 1997, 1998a, 1998b, 1999; Halliday \& Matthiessen, 1999; Kopple, 2002). A salient feature of scientific text is the extensive use of grammatical metaphor, in which a semantic element that would be construed congruently through one grammatical choice is reconstrued through a different grammatical choice. The most frequently discussed type of grammatical metaphor is nominalization, in which a process, which would congruently be construed as a verb, is instead construed as a noun, e.g., evaporate becomes evaporation. In a second common grammatical metaphor, an attribute, which would congruently be construed using an adjective, is instead construed using a noun, e.g., long is, e.g., length. In a third type, the relationship between two figures, which would congruently be expressed using a relator construed through a conjunction, is instead expressed as a process using a verb. For example, causation, which might congruently be expressed using the conjunction "so," is instead expressed using the verb "determines." 
In scientific text, these features combine to form a common or "favorite" clause such as this one:

\section{[Rapid changes in the rate of evolution] are caused [by external events].} (Halliday, 1998b, p. 59).

The Subject of this clause is a figure construed as a nominal group; it is followed by a semantic or logical relator construed as a verbal group; this is followed by a second figure construed as a nominal group.

Halliday (1998b) has described the logogenesis, or unfolding of meaning, within scientific text. Logogenesis contrasts with other time frames: Ontogenesis refers to development across the lifespan; and phylogenesis refers to development across evolutionary time (Halliday \& Matthiessen, 1999, pp. 17-18). In the logogenesis of scientific text, a semantic element, such as a figure, is introduced in a clause. In a subsequent clause, this semantic element may be nominalized, allowing it to serve as the Subject of this clause. This comprises compacting, in that a semantic figure, which would be congruently construed as a clause, is now reconstrued at the lower grammatical rank of a word or phrase. This allows it to function as part of a subsequent relationship between figures, such as complex causation. This process of reconstrual, compaction, and thematization can be then be repeated; the result is that a theory is constructed and supported through an extended chain of reasoning. These processes can be found to some extent in written texts in the humanities and social sciences; however, the use of the grammatical metaphor of nominalization is very frequent in the natural sciences (cf., Hood, 2011; Maton, 2011; Martin, 2011).

In this way, professional scientific writing realizes two motifs. The first motif is technicality, the creation of a taxonomy of technical terms. This technicality expands the noun as 
a resource for meaning. It also distills this meaning to a limited, abstract sense so that the term functions as part of a theory; for example the term avis connotes a place in a taxonomy, whereas the everyday term bird does not (Halliday, 1998b, p. 64). Consequently, scientific texts are systemic in the sense that they create a set of inter-related terms that can be taken up and used in subsequent texts. The second motif is reasoning or logicality, in which the text construes a theory, that is, a set of propositions which provide an explanation and supports this explanation with evidence (Halliday, 1998b, 1999).

Halliday proposes that congruent discourse and scientific discourse project two different worldviews. Congruent discourse construes the world as dynamic, a space where experience is comprised of human or non-human agents and concrete things, which participate in visible processes of change, in a perceptible manner and set of circumstances. Conversely, scientific discourse construes the world as a place that is synoptic: Abstract or virtual entities are related to one another through processes that are abstract and timeless. A given professional science text works to construct knowledge, beginning somewhat congruently, and progressing toward a more technical, rational, and synoptic form. Academic text in the humanities and social sciences also shows synoptic properties, but to a lesser degree, relying more on grammatical complexity, and less on nominalization and lexical density, to build knowledge (Christie \& Macken-Horarik, 2011; Coffin, 2004; Schleppegrell, 2011).

\subsection{Systemic Functional Studies of Student Academic Writing.}

These findings raise important questions about the linguistics of students' scientific texts, particularly in the case of writing to learn in science. How is experience construed linguistically as the text unfolds? Do student writers show a process of logogenesis similar to that found in professional texts, or some other pattern? To date, most previous research on the linguistics of 
students' academic writing has employed an ontogenetic timeframe, using a cross-sectional approach to compare the texts written by students' at various educational levels. These studies have shown that the texts of elementary writers tend to comprise genres that are relatively descriptive, implying a relatively dynamic construal of experience; the texts of late elementary and secondary students more frequently comprise more abstract genres, such as scientific explanations and arguments, which make greater use of a synoptic construal of experience (Christie, 1998; Christie \& Derewianka, 2008; Martin, 1989). The most extensive developmental study found that the texts of younger students include concrete participants construed through nouns, perceptible actions construed through verbs, and relationships among events construed as conjunctions linking clauses; they show fewer features of synoptic texts, such as grammatical metaphor (Christie \& Derewianka, 2008). Explanations, for example, show a progression in abstraction throughout the late elementary and secondary grades: Sequential explanations connect a series of events; factorial explanations identify multiple simultaneous causes; and causal explanations include abstract processes (Christie \& Derewianka, 2008; Veel, 1997). Similar contrasts between congruent and synoptic discourse appears in other academic disciplines such as history, with younger writers producing more congruent texts, and students at higher educational levels producing more synoptic texts (Coffin, 2004). Other SFL research has taken an educational approach, showing that with explicit instruction, modeling, and practice, students can learn to write texts more similar to those found in academic disciplines (Fang \& Schleppegrell, 201; Macken-Horarik, 2002).

However, although the ontogenesis of students' academic writing has been explored extensively, the logogenesis of writing to learn has not yet been investigated. What is the linguistic nature of this process? For example, how do students map semantics onto grammatical 
choices, and how does this change over the course of a given text? Such an investigation could help to inform decisions about the linguistic characteristics that teachers could expect or encourage in writing to learn activities.

It may be the case that all acts of writing involve creation of meaning, in the sense that each text is, to some degree unique. However, there is an important distinction to be made (Christie, 1989, pp. 193-196; Halliday \& Matthiessen, 1999, pp. 384-387). In some texts, the writer expresses meanings similar to those that he or she has expressed previously; for example, professional scientists typically construct the ideas and language for their articles prior to writing the manuscript text itself, in spaces such as laboratory discussions with colleagues, email messages, and draft manuscripts (Cronin, 2004; Yore, Hand \& Prain, 2002). Consequently, the manuscript submitted for review may simply reiterate these meanings in a polished form. However, in other instances, the writer may create a text that includes meanings that he or she has not expressed before; for example, a student may have previously expressed a scientific misconception, and now in the course of writing a new learning journal entry realizes that this former conception was incoherent, and constructs a more valid one (e.g., Klein, 2004). This latter case is of interest in writing to learn. Writing to learn is particularly interesting from an SFL point of view, because logogenesis specifically concerns the way in which experience is construed in scientific discourse. Construing a new meaning, rather than a familiar set of meanings, is an instance of substantial "meaning-making." However, the linguistic nature of this process is unknown. It might be expected to differ from that of professional science text. As Halliday (1998b, p. 93) wrote, “...the nominal grammar would not have served very well in the primary construal of experience; you have to know the answers before you start." 
Some authors have described students' discourse during the construction of new concepts or explanations; these have shown a movement toward nominalization (Massoud \& Kuipers, 2008; Viechnicki, 2008; Wright, 2008). However, in these studies, writing has been relatively incidental to other activities such lessons from the teacher, small group discussions, and reading. Consequently, the written texts examined in these studies have been very brief and fragmentary. Conversely, examining a writing to learn text would be helpful in understanding the linguistics of students' knowledge construction specifically during writing. In a related point, previous studies have focused almost entirely on nominalization. This raises the question of what other forms of grammatical metaphor students may use in writing, and how these function in the unfolding of a given text.

The present study focused on learning journals. In SFL, the genre of a writing activity is conceived in terms of social purpose. The genre that was the focus of the present study was the journal entry (e.g., Bangert-Drowns et al., 2004; Drabick et al., 2007; Nückles et al., 2009). Its purpose is primarily to support learning through reflection on some experience, so the main readership is the writer himself or herself. Learning journals are also read by the teacher to assess learning formatively, and thereby inform subsequent teaching. The text is typically elicited through a reflective thinking prompt; it is typically completed in a single session resulting in a single draft; and it is typically composed individually.

\subsection{Purpose of the Present Study}

This study investigated the linguistics of students' knowledge construction during writing. Students observed two demonstrations concerning one of two scientific principles. Each student then wrote a reflective journal-style note to interpret this experience. For analysis, four texts were selected in which students constructed new explanations in the course of writing. 
Analysis focused on two research questions: First, how did the construal of semantic elements (things, processes, attributes) through grammatical choices (e.g., nouns, verbs) change during the composition of each text? Second, how did this construal operate in the students' construction of explanations (theorizing)?

\section{Materials and Method}

\subsection{Overview.}

The texts analyzed here were drawn from a larger study on writing to learn in physics (Klein, Piacente-Cimini, \& Williams, 2007). In total, 72 university students who were not science majors participated. Each student created a learning journal entry explaining one of three science topics: buoyant force of a fluid; components of projectile motion; or forces internal to a system. Students initially completed a brief pretest specific to the particular science topic. They then observed two demonstrations that were based on the same topic, e.g., two demonstrations concerning the buoyant force of a fluid. Next, they constructed an explanation of the demonstration using one of three discourse modalities: speaking, writing, or think-aloud writing; the samples analyzed here came from the writing condition. Finally, students completed a brief post-test to assess their understanding of the science topic; the comparison of the pretest and post-test allowed us to assess students' learning during the writing interval. The method will now be presented in greater detail.

\subsection{Participants.}

The participants were students at a large Canadian university. Because we were interested in students constructing explanations that were new to them, participants who were not science majors were recruited using posters displayed in faculties other than science (e.g., music, social science); thus students were drawn from a wide range of disciplines in the humanities, social 
sciences, and fine arts. The larger study from which this sample was drawn comprised 72 participants, and took place over approximately two months. To achieve depth of analysis, it was necessary to select a small sample of four texts. All four participants spoke English as a first language. The selection process is described in detail in the Analysis section below.

\subsection{Procedure.}

The participants answered a series of pretest questions to assess their initial understanding of the specific physics topic about which they would write. Each question comprised a predict-and-explain item, in which a scenario was presented to the student, who predicted what would happen next, and explained why it would happen (Appendices One and Two). Two of the scenarios comprised demonstrations that the students were about to observe; one comprised a question identical to the first question of the post-test. The students selected for this analysis predicted the outcome of at least two of the three scenarios incorrectly, and none offered a scientifically valid explanation for any scenario.

For each of the science topics there were two demonstrations. The demonstrations were based on physics principles about which most individuals hold misconceptions (Brown, 1989; She, 2002); they were designed to challenge these misconceptions, and to allow the students to construct more valid explanations. The pair of demonstrations observed by each student differed from each other perceptually, but shared a common underlying physics principle, so they could be considered analogs of one another. For concise presentation here, two of the three science topics were selected.

The first science topic was the buoyant force of a fluid, that is, the principle that the density of a fluid determines the buoyant force that it exerts. This principle differed from the beliefs of most participants, who thought that the buoyancy of an object depends only on the 
characteristics of the object itself. The first demonstration of this principle, Three Liquids, comprised a large beaker containing two layers of liquid. The lower (denser) liquid was labelled 'salt water' and the upper (less dense) liquid was labelled 'oil.' A plastic vial labelled "fresh water" was placed in the beaker, where it sank to the boundary between the saltwater layer and the oil and remained suspended there. In the second demonstration of this principle, Aerated Cylinder, a wooden ball initially floated in a large cylinder of water. An aquarium air pump was connected to an air stone at the bottom of the cylinder. Most participants predicted that when the pump was switched on, the rising bubbles would lift the ball; in fact, when the water filled with bubbles, the water and air mixture was less dense than the water had been, so the ball sank.

The other science topic was components of projectile motion. The principle underpinning these two demonstrations was that the components of projectile motion (horizontal velocity and vertical acceleration due to gravity) are independent of one another. The first demonstration of this principle was the Funnel Cart, a small vehicle with a vertical tube mounted on top. The cart rolled forward, and the ball was launched vertically by a spring. Most participants predicted that the ball would fall behind the cart, because they believed that an object falling vertically slows down in the horizontal direction; in fact, the ball travelled with the same horizontal velocity as the cart, and dropped back into the funnel. The second demonstration of this principle was Balls Dropped and Shot. A bracket sitting on a table held a spring-loaded rod and two balls. The lever was released, and one ball was projected horizontally, while the other ball was dropped vertically. Most participants believed that a ball falling on an arc would drop more slowly than one falling in a straight line, so they expected that the latter would hit the ground first. Actually both accelerated vertically at the same rate due to gravity, and landed at the same instant with a single, audible 'click.' 
This was followed by the discourse task. The discourse task was the only means of learning provided; there was no explicit teaching or discussion of the concepts for this task. Instructions for the writing task were similar to those used by Kurtz, Miao and Gentner (2001): "Please [talk / write / write and think aloud] and compare the two demonstrations. Think about what they have in common. Describe what is happening and explain why. Please answer as fully as possible." (For the present analysis, texts from the writing condition were selected).

Participants were not given any additional guidance concerning the task. They wrote for as much time as necessary; all completed the writing activity in 30 minutes or less.

Finally, each participant completed a post-test specific to a topic: buoyant force of a fluid, components of projectile motion, or forces internal to a system. The first through sixth items presented novel scenarios, and asked participants to predict the outcome, and explain why this outcome would occur; the first of these questions was identical to the first pretest question (see Appendices One and Two). The seventh through tenth questions comprised cloze items that required students to compose explanatory statements. The total data collection required up to one hour per participant.

\subsection{Analysis.}

As noted above, four texts were selected for further analysis. Because the topic of this paper is logogenesis, it was necessary to present the development of individual texts in detail, from beginning to end. Because this analysis focuses on writing, texts in this condition, rather than speech or think-aloud conditions, were eligible for selection. Because this analysis focuses on knowledge construction, the selection was narrowed to 19 students who showed evidence of the construction of new explanations during writing. These were defined as students who offered no valid explanations during the pretest; they provided scientifically valid explanations at the end 
of the written text; and at the post-test, they provided valid explanations in response to novel problems, and in response to the item that was repeated from the pretest. Within each of the two science topics, two texts were selected to represent the range of different writing styles: One text was selected to represent a more dynamic or speech-like style characterized by less grammatical metaphor; and one text was selected to represent a synoptic style characterized by more grammatical metaphor. It is acknowledged that this was not a random sample of students, instead was selected to represent the similarities and differences in the linguistic nature of texts that showed evidence of learning during writing.

Systemic functional linguistic analysis focuses initially on the clause, which is considered to comprise a unit of experience. It includes three systems: the system of mood, the system of information focus, expressed in theme and rheme; and the system of transitivity, expressed in the use of grammatical choices to represent aspects of experience. Because our theoretical interest concerns the way in which grammatical resources are used to construe various elements of experience (semantic elements), and because these texts were rich in this respect, the system of transitivity was the principal focus of this analysis.

The transitivity of clauses is considered here with respect to three broad categories. Material clauses represent physical processes, or more accurately, they represent processes as physical; these processes include doing, acting, creating, and changing. They include an Actor which is doing the action, and may include other participants, such as a Goal, the object to which the action is extended. Mental clauses represent processes such as thinking, feeling, and perceiving; grammatically, they must have at least two participants: the Senser who is a human or anthropomorphized participant, and the Phenomenon, which is the thing that is sensed, and can comprise a wide range of elements, including objects, events, acts, or facts. Relational 
clauses represent the semantics of being, having, or symbolizing; each clause includes a Carrier and an Attribute; (or a Token and a Value, respectively). These three categories can be further subdivided (Halliday \& Matthiessen, 2004); however, to keep the number of technical SFL terms in this paper moderate, this analysis is restricted to these three broad categories. Additionally, we will use the familiar traditional school grammar terms "Subject" and "Object" or "Complement," rather than the SFL terms specific to each type of process (e.g. Actor, Goal, etcetera).

In the first step of the analysis, the texts were segmented into ranking clauses (that is, clauses not embedded within other clauses); within each text, each sentence was numbered, and each clause within the sentence was assigned a letter, e.g., 5 b refers to sentence 5 , the second clause. Second, each clause was categorized into one of the three broad types of transitivity: material, mental, or relational. Thirdly, the words in each clause were coded with respect to semantic category as participants, processes, circumstances/manners, and relators.

\section{Results}

In this section, we will present an analysis of one student's projectile text, and then to be concise, comment briefly on a second student's projectile text. Then we will present a buoyancy text, and comment briefly on a second student's buoyancy text.

\subsection{Projectile Motion, Patrick’s Text (\#315).}

Patrick was a 22 year old anthropology student with no previous secondary school or university courses in physics. At pretest, he predicted and explained the outcome of all three scenarios incorrectly; for example for balls dropped and shot, he said, “...the (horizontal) speed of the ball determines how gravity will act on it." However, after writing, his post-test score was high, and he explained that the relationship between horizontal velocity and acceleration due to 
gravity is that they are "independent." He appears to have constructed a valid explanation during writing.

Patrick's text (see Table 2) comprises three sections, which we dubbed as follows: The funnel cart demonstration, the balls dropped and shot demonstration, and the conclusion.

Patrick begins by describing the first demonstration using four material clauses (1a-1d). Each clause construes one observable event; the Subject of each clause is a concrete object expressed by a definite nominal group (e.g., the cart); the processes are observable, and construed by verb phrases (e.g., was moving). Circumstances are construed using prepositional phrases (e.g., out of the pipe). Each event is represented in a distinct clause. The relationships between the clauses are temporal. Thus, the first few clauses of the text construe experience congruently and dynamically.

Then in sentence 2, Patrick congruently recounts his expectations and the rationale for them. He begins with a mental clause; the Subject is the writer $(I)$; the process is a mental verb (expected); the verb projects a material clause that reports the expected event (e.g., that the ball would fall behind the cart). Reasoning in this section is realized across clauses, with the juxtaposition of the expectation and rationale for this expectation comprising five clauses in total. In Sentence 3, Patrick begins to build relations among the semantic elements introduced earlier in the text; for example, The ball seemed to follow the cart relates the participants and processes from clauses1a-1d to one another; even when the former was airborne, alludes to clauses 2a-2d. This sentence is particularly important in Patrick's explanation because it introduces for the first time the notion that the motion of the ball and the motion of the cart are similar in some way. 
Patrick has difficulty explaining the funnel cart demonstration $(4 a-4 c)$, so he introduces a novel analogy (4d-4h) using a complex grammatical metaphor: The Subject of $4 \mathrm{~d}$, it, is a grammatical metaphor, in which a set of events is re-construed as thing-like using a pronoun. This allows Patrick to make them a topic for further comment. Similarly, the Complement, the experience of travelling in a bus, is a nominal group with an embedded prepositional phrase, which cataphorically references a series of events that Patrick is about to introduce using a series of material clauses. The Subjects of some of these clauses are concrete objects construed as members of a general category; for example, an object (4e-4f) has the generality to represent the participants on both sides of an analogy: the funnel cart demonstration and the bus anecdote. The circumstances of these clauses introduce two virtual spaces: horizontal \{plane\} and vertical plane; this is the first time that Patrick makes the important distinction between horizontal and vertical spaces for movement. They are virtual in the sense that the distinction between these two dimensions is imposed conceptually, rather than found in perception. Apparently, the bus analogy makes the division of motion into horizontal and vertical components possible for Patrick: From the viewpoint of the rider, a fellow passenger jumping up and down appears to move vertically; however, from the viewpoint of a bystander, the bus itself is moving horizontally, and so the passenger must be moving horizontally as well. Patrick then offers an additional analogy in Sentence 5, and then expresses doubt about understanding the demonstration in Sentence 6.

The second section analyzes the balls dropped and shot demonstration (7a-7b). First, Patrick congruently uses material clauses to describe these events. Then Clause 8a begins to build relationships among the events, taking up the participants from the previous two clauses (They), and congruently construing the circumstance using a prepositional phrase, hit the ground 
at the same time, to reconstrue these two events into one figure. He then introduces an additional analogy inspired by a pretest question to interpret the second demonstration (9a-10c). The pretest question had referred to a carnival game, in which a ball launcher is aimed horizontally at a hoop that is about to drop; when should the player launch the ball to send it through the hoop?

(Appendix One). In fact, the ball and the hoop would accelerate downward at the same rate due to gravity, so the ball should be launched at the same instant that the hoop is dropped. Patrick constructs this analogy using a grammatical metaphor: The Subject, this experiment, takes up the sequence of figures from $7 \mathrm{a}$ to $8 \mathrm{~b}$, and construes them as a participant using a nominal group (this experiment); the Complement, the question, construes a proposition as a virtual thing, using a nominal group which is then postmodified with two embedded clauses.

In Clause 10a, Patrick expresses some doubt about his developing explanation, although it is actually valid: "It doesn't seem plausible to me that the speed of the ball is irrelevant." This clause is highly metaphorical and complex; we will unpack it from the middle outward: Speed of the ball, nominalized here using a nominal group, would more congruently be realized as a circumstance of manner e.g. 'how quickly the ball travelled'. This nominalization allows it to serve as the carrier for the attribute irrelevant, meaning here that the speed of the ball does not affect its path. The term "irrelevance" correctly approximates the standard physics conception that horizontal velocity does not affect vertical acceleration due to gravity. However, Patrick doubts his own correct explanation, taking it as the Subject of the clause, and ascribing to it a relational process: doesn't seem plausible. This is the third time in the text that he has tentatively proposed an explanation similar to the standard model, but then doubted it. Then in 10b-10c, Patrick reconstructs this doubt into a valid qualification on his new conception, using a brief thought experiment, construed using two material clauses linked by conjunctions. 
In the next, brief, section (11a-c), Patrick explicitly remarks on the shift from his initial explanation to the final one. This section of the text is rich in grammatical metaphor: The Subjects of these clauses include the following: a proposition construed using a nominal group (11a); a circumstance of manner of motion construed using a nominal group (11b); and a manner of motion construed using a clause (11c). In these clauses, Patrick takes up complex elements of experience from earlier in his text, and incorporates them into the explanation; he also takes up beliefs from earlier in his text, and reflects upon them. The conclusion of the text (12) is also highly metaphorical. The Subject, the experiments construes a series of events as a thing; the complements are a virtual entity, gravity, and a nominalization of a circumstance of manner of a process, horizontal motion.

To summarize, as the text unfolds, it shows the following patterns: First, Patrick describes each demonstration in a mode that is congruent with experience, using material clauses with new information provided in the circumstances, and relationships between events construed across clauses. Second, he uses mental clauses projecting material clauses to narrate the changing relationship between his expectations and the actual events. Third, in the middle part of the text, Patrick introduces new analogies to interpret the events. Fourth, these analogies, as well as the causal and explanatory statements, show increasing use of grammatical metaphor as the text unfolds; the Subjects of the clauses include complex and varied semantic elements (events, propositions, circumstances of manner of processes), construed using pronouns or nominal groups; these allow the writer to take up the events that were described earlier in his text, and topicalize them for further discussion. At the same time, the verbs comprise increasingly abstract relations of complex causation and evidence; and the predicates (complements of the verbs, and 
the circumstances) include increasingly complex semantic elements, construed with similar devices.

\subsection{Projectile Motion, Naomi's Text (\#347).}

For conciseness, this section will not give a line by line analysis, but instead highlight the similarities and differences to Patrick's text. Naomi was a 21 year old woman, majoring in English, with no secondary school or university courses in physics, and one university course in the philosophy of science. On the pretest, she predicted the outcome of two of the three scenarios incorrectly, and initially conceptualized horizontal velocity and gravity as working in opposition to one another; for example for the funnel cart demonstration she predicted that "if the ball is shot with greater or less force than gravity, it won't go in[to the funnel]." However, after writing, she showed clear evidence of progress, concluding on the posttest that "The gravitational force on an object is always the same-whether the object is in motion or not."

Overall, Naomi's text (see Table 3) proceeds by explaining the first demonstration, then explaining the second demonstration, then comparing the two demonstrations, and finally drawing a conclusion. Like Patrick, Naomi initially describes each demonstration using one material clause to construe each event, and connects the clauses using conjunctions and adverbs to express relationships such as simultaneity and causation (2b-d; 4c). However, her description of the events is brief, and she moves more quickly than Patrick to integrate elements of each demonstration using clauses that include grammatical metaphor. For example, in discussing the funnel cart, she uses relational clauses to metaphorically construe the ball's motion in terms of possession of an attribute, shared the same speed and direction of motion of the cart (2e; also 4a, $4 b, 7 b-c, 8 a-c)$. 
More generally, throughout the text, she regularly uses grammatical metaphor in the Subjects of the clauses, nominalizing a variety of entities, such as propositions $(1,5 \mathrm{a})$, sets of events (3a, 9a), circumstances of manner of processes (4a), and abstract entities (4b, 5b, 6c, 7b). Unlike Patrick, who used pronouns frequently to nominalize a variety of elements of experience, she does so only once (3a), and in all other instances, nominalizes various semantic elements through nouns and nominal groups (1, 2e, 3a, 4a, 5a, 5b, 6c, 7b, 8b, 9a). Consistent with this, like Patrick, she sometimes uses material clauses and expresses new information in the circumstances $(2 \mathrm{~d}, 4 \mathrm{c}, 6 \mathrm{~b}, 6 \mathrm{c}, 7 \mathrm{a})$. However, she more often uses relational clauses $(2 \mathrm{a}, 2 \mathrm{e}, 4 \mathrm{a}, 4 \mathrm{~b}, 7 \mathrm{~b}, 8 \mathrm{a}, 8 \mathrm{~b}$, 9a), several of them centered on abstract processes. Consequently, information about motion is expressed in the Complement, often comprised of grammatical metaphors, such as it [the ball] shared the speed and direction of motion of the car $(2 \mathrm{e} ; 4 \mathrm{~b}, 7 \mathrm{~b}, 8 \mathrm{a}, 8 \mathrm{~b})$; here the manner of motion of the ball and the car are reified and compared. More generally, both kinds of clauses offer explanations that refer to abstract or virtual entities (4b, 6c, 7b, 7c, 8a). In this section, the relators between clauses then, do not link specific concrete events, but instead link abstract propositions or ideas about events, for example, by comparing the way in which two demonstrations both violated the writer's expectations (4a-4c; 5a-5b).

Like Patrick, Naomi reflects on the differences between her expectations and the actual results of the demonstrations. However, whereas Patrick used mental process clauses in the first person and past tense to present a brief personal narrative of changing ideas, Naomi presents her changes in beliefs in terms that are more impersonal, using mental state verbs that are predicated of no one in particular (e.g., 6a); or using relational clauses with no personal Subject e.g., ...the expected results might match the actual results... (5b; also 3a); or she reifies the knowledge itself as a participant $(9 \mathrm{a})$. 
Overall then, Naomi's text shows the same general characteristics as that of Patrick: She begins her text by using material clauses to describe the demonstrations, and progresses to greater use of grammatical metaphor. However, her text shifts more quickly from the congruent mode of construal to the more synoptic mode exemplified by the "favourite clause" type of science.

\subsection{Buoyant Force of a Fluid, Alexis' Text (\#339).}

Alexis was a 23 year old kinesiology major, with no secondary or university courses in physics. On the pretest, she predicted the outcome of all three scenarios incorrectly, and incorrectly explained her predictions by stating that regardless of the fluid in which an object is placed "...there is no higher level that something can float." On the post-test she offered the improved explanation that an object floats if "its weight is less than the solution."

In the first section of her text (Table 4; Sentences 1-5), Alexis identifies elements that both experiments had in common. For example, in the first sentence, the Subject, the experiments, comprises a dead grammatical metaphor in which a series of figures is construed as a thing using a nominal group; the relational process, were showing, expresses a symbolizing relationship; and the Complement, the effects of a weighted mass on a solution, is a grammatical metaphor in which a causal relationship, which would congruently be expressed using a conjunction, is instead construed using a nominal group with an embedded prepositional phrase. Throughout this first section, she used material and relational clauses to describe concrete elements common to the two experiments; however, the comparison of the two demonstrations is superficial, and the explanation does not progress.

In the second section (6a-8c), Alexis discusses the first demonstration in greater depth. In 6a, she introduces for the first time the importance of the difference in weight between the 
liquids, a dead grammatical metaphor in which an attribute of a participant is construed metaphorically as a thing using a familiar noun. In 7a-7c, material clauses are used congruently to describe the experiment; the Subject of each clause is a type of material construed as a noun, e.g., the water; the process is perceptible, floated; and information important to the explanation is added in the circumstance using prepositional phrases, e.g. on top of the salt water. Each clause comprises one event, and conjunctions between clauses express temporal and spatial relationships between these events. Clause 8a introduces a very brief argument; the Subject is the demonstrative This, which refers back to the three descriptive clauses 7a-c, metaphorically nominalizing all three events as things, and presenting them as a source of evidence; the mental process verb shows introduces the explanation. Then in $8 \mathrm{~b}-8 \mathrm{c}$, Alexis uses relational clauses to congruently and validly present an explanation of buoyancy in terms of liquids being more dense or less dense. Dense is a slightly abstract term, in the sense that the density of these liquids is concrete but not readily perceptible, and so must be inferred. Here, the relationship between clauses conjoins ideas (8b-8c).

The section concerning the aerated cylinder demonstration (9a-11a) grammatically parallels the previous one: Alexis begins by using material and relational clauses to congruently describe the events (9a-10b). Then 11a introduces a brief argument: The demonstrative this is a grammatical metaphor-it uses a pronoun to construe the events described in the three previous clauses. This allows them to serve as the Subject for the relational verb means, which metaphorically realizes a relationship of implication to a set of four clauses congruently describing concrete events. The figures in these four clauses are reported in chronological order, linked mainly by conjunctions expressing temporal and causal relationships; the exception is it $\{=$ the air $\}$ decreased the water's mass so much, where the complex causal relationship of 
diminishing is expressed by the verb within the clause. In this section, Alexis uses the terms mass and weight interchangeably rather than the standard term density. She concludes (12) with a summary that refers to the weight of solutions.

In summary, as Alexis's text unfolded, it showed the following patterns in mapping semantic elements to grammatical elements: She began with a technical but vague explanation; then she described each demonstration congruently using material clauses that reported the events and relational clauses that identified the types of materials. Second, the explanations themselves were largely congruently framed in relational and material clauses, with causal relations distributed across clauses using conjunctions. Third, epistemic relations were construed in verbs of symbolizing, as if the experiments "spoke" for themselves. Fourth, within the discussion of each demonstration, the clauses shifted toward increasing grammatical metaphor in the Subjects of the clauses; these anaphorically took up entire events previously mentioned in the text, and metaphorically treated them as things, allowing them to operate in causal explanations and arguments. At the same time, the verbs in most clauses congruently represented visible processes. Overall then, the text showed a shift from relatively congruent, to somewhat synoptic.

\subsection{Buoyant Force of Fluid, Jennifer's Text (\#352).}

Jennifer was a 23 year old English major, who completed several secondary school science courses including physics, and one university astronomy course. On the pretest, she predicted all three scenarios incorrectly or responded that it was impossible to predict what would happen next, and did not provide any explanations for her predictions. After writing her text, on the posttest she explained that "some liquids provide more buoyancy than others because they are denser or heavier." For conciseness, we will briefly outline the ways in which her text was similar to, and different from, that of Alexis. 
Jennifer, like Alexis, opens her text (see Table 5) with a general, abstract statement that does not advance the explanation (1a). She then uses material clauses to compare the descriptions of events (2a-3b); much of the information critical to the explanation appears in the circumstances, construed through prepositional phrases; relationships between events are expressed by a conjunction and an adverb, both linking clauses.

She then shifts toward comparing elements of the two demonstrations (4a-4d) using relational clauses. This involves some grammatical metaphor, in that the Subject participants are comprised of multiple figures (events), which are construed using definite nominal groups (4a) or pronouns $(4 \mathrm{~b}, 4 \mathrm{~d})$, or elisions $(4 \mathrm{c})$; the predicates construe the demonstrations in terms of concrete attributes (4a-c). However, the explanation does not progress significantly in this section.

Most of the progress in creating the explanation is made when Jennifer, discussing the first demonstration, offers a brief valid explanation using a relational clause (5a); then in $5 \mathrm{~b}$ she uses the conjunctive phrase in order to to connect this with the material clause describing the event. Similarly in 6 a she provides a congruent description, which she uses to justify an explanation (6b-6c). Here, the relationships among clauses early in the text are additive and temporal; later in the text, they are logical. However overall, the text is relatively congruent throughout; for example, only one clause has a Subject that represents a proposition or process; and none of the clauses have a verb that expresses a complex logical-semantic relationship.

\section{Discussion}

\subsection{Research Question 1: How Did the Mapping Between Semantic Elements and Grammatical Choices Develop Throughout the Texts?}


The purpose of this study was to examine the linguistics of writing to learn. The analysis focused primarily on the way in which semantic elements were construed through grammatical choices, the development of this mapping as the texts unfolded, and the role of grammatical metaphor in reasoning. It appeared that these participants constructed new explanations during writing: The science pretests showed that prior to writing, they were unable to make accurate predictions about most scenarios and unable to explain any of their predictions using scientific principles; similarly, the opening sentences of each text offered only vague generalizations. However, by the end of their texts, the participants offered valid explanations. Moreover, none of the writers planned (outlined) their texts in advance, or revised them after writing, so they appear to have generated the ideas roughly at the time that they transcribed the texts. They then scored well on the post-test, which also supports the interpretation that these students learned new scientific principles during writing.

For all four writers, the relationships between semantic elements and grammatical choices showed the following similarities: Firstly, each writer initially described the experience of one or both demonstrations congruently: For both science topics the writers used material clauses to report events; in the buoyancy task, they also congruently used relational clauses to describe concrete attributes of objects. Secondly, as the writers discussed each demonstration, they gradually increased their use of grammatical metaphor. Grammatical metaphor occurred frequently in the Subjects of the clauses; semantically, these Subjects comprised increasingly complex elements of experience, such as figures (events), attributes of objects, and circumstances of manners of process; 
these were construed using demonstratives, and nominal groups which sometimes included embedded clauses.

Thirdly, for all four participants, the motif of reasoning was largely construed congruently; reasoning was distributed across clauses, which were related by conjunctions and adverbs. This was particularly true early in each text. The causal explanation of each demonstration was realized through a series of material process clauses linked by conjunctions. The epistemic work of providing evidence for these explanations was realized through mental process verbs that projected material clauses, or through relational clauses that represented these experiences more impersonally. Both types of clauses were used to note unexpected results, and to justify new explanations. Fourthly, toward the end of each participant's text, the use of grammatical metaphor increased; it was often used to express a relatively general conclusion about a scientific principle. In these clauses, the Subject frequently represented a complex semantic element, such as a figure (event) or proposition; the verbs, in some instances, expressed abstract relations concerning complex causal relationships or evidential relationships.

Although all four texts showed these trends, the extent to which grammatical metaphor was used was a matter of individual style. The ranking was roughly this: Jennifer's buoyancy text was most congruent, progressing from entirely congruent discourse early in the text, to some use of grammatical metaphor in the Subjects of some later clauses, but not in the verbs. Patrick's projectile text and Alexis's buoyancy text showed a moderate level of grammatical metaphor, progressing from congruent clauses early in the discussion of each demonstration, toward a mixture of congruent and synoptic elements at the end. Naomi's projectile text was most synoptic in style, 
progressing from the use of nominalized Subject participants and congruent predicates early in the text, to grammatical metaphor in both the Subject and the predicate later in the text.

\section{2. Research Question 2: How Did this Construal Support Students' Theorizing?}

The second question concerned the way in which this construal was employed in students' construction of knowledge, or in SFL terms, theorizing. This process will be discussed in relation to Halliday's (1998b) discussion of the semiotic potential of modern science text using five key concepts: expanding, transcategorizing, compacting, distilling, and theorizing. The discussion will show that, consistent with the SFL analysis of logogenesis in scientific text, these writers showed a process of transcategorizing and compacting that supported a motif of reasoning or logicality; however, the texts show little distilling or expanding, and did not show a technicalizing motif.

The analysis above documented the way in which these writers transcategorized semantic entities. In these texts, this transcategorization most frequently comprised the metaphorical transformation of aspects of experience comprising a variety of complex semantic classes (figures, sequences of figures, propositions, processes) into things, expressed as nouns, nominal groups (sometimes modified with embedded clauses), and demonstrative pronouns. Additionally, attributes of objects were grammatically reconstrued as things, and relations between figures were reconstrued as processes.

Nominalization and pronominalization_in turn allowed compacting, in which semantic elements, which would congruently be expressed using grammatical units high in rank and large in size, were compacted and expressed in grammatical units lower in rank. Notably, figures, which would congruently be construed using an entire clause, and propositions, which would be 
congruently construed using two or more clauses, were compacted to comprise individual words or phrases.

In turn, the process of compacting allowed these texts to carry forward the motifs of theorizing, particularly, logicality. Once an entire event or proposition was compacted into a single nominal group or pronoun, then it could serve as the Subject of a subsequent clause, and the writer could comment on it further. Conversely, if the writers had represented these large semantic elements in their congruent, expanded form, with a full clause for every event, then by the middle of the text, each sentence would have been tremendously long. Thus, nominalization and compacting appeared to aid the writers in building a complex network of ideas, while keeping the text manageable and intelligible. This is the same function that nominalization serves in professional scientific text (Halliday, 1998b; Martin, 2011).

The principal form of logicality in these texts was explanation. As noted in the introduction, in professional scientific text, causal explanation is often expressed in a clause in which the Subject comprises a figure construed as a nominal group, the verb expresses a complex causal relationship, and the Object or Complement comprises another figure construed as a nominal group. In the present texts, causal explanation was expressed along a grammatical continuum, from congruent to relatively synoptic.

We have referred to the other form of logicality as epistemic. In scientific text, evidential relationships are frequently realized through a single clause in which two nominal groups, each construing a figure, are connected by a verb (Halliday, 1998b). These verbs are abstract, and frequently predicated of events or phenomena, rather than persons (e.g., proves, suggests, demonstrates, implies). However, in the present study, the more common realization was the congruent one, in which a mental process projected a material clause. They comprised personal 
verbs of thinking (e.g., expected, thought) or relational verbs (e.g., seemed), and they were frequently tensed in the past, indicating particular events, rather than timeless generalizations. In short, rather than a professional discourse of textual argumentation in which one abstraction is offered as evidence for another, the epistemic sentences in these texts comprised brief personal narratives about the writer coming to understand particular events. This finding somewhat parallels the results of the analysis of professional academic writing in the humanities, in which knowledge claims are legitimated through a visible self, who comprises the participant in clauses, and testifies to specific observations or inferences using mental verbs to project clauses (Hood, 2011).

Although the logicality motif of scientific text was ubiquitous in this study, technicality, or the taxonomic motif of professional scientific writing, was almost entirely absent. Recall that in scientific discourse, nominal groups are used to construe various kinds of semantic entities, creating a taxonomy or system of theoretical terms that can function in subsequent texts. In the texts analyzed here, the writers coined a few terms that could be used beyond the immediate context (e.g., horizontal velocity). However, they more often relied on the Anglo-Saxon repertoire of dead grammatical metaphors found in everyday English, e.g., they used speed to reconstrue a manner of process as if it were a thing, and used weight to reconstrue an attribute as a thing. Additionally, the writers used relatively familiar Latinate terms to nominalize a variety of semantic elements (e.g., distance, motion, gravity, force). In its use of few technical nominalizations, this writing was more similar to the humanities rather than the sciences; for example, in historical texts, the participants of clauses frequently include a head that is an abstract but non-technical noun, e.g., "act" (in the legal sense), "support," or "criticism" 
(Shleppegrell, 2011). Consequently, these texts did not exemplify the expansion of the noun as a semiotic resource.

In a related point, it was noted above that whereas professional scientific texts achieve compaction primarily through nouns, these student authors relied heavily on demonstrative pronouns. These were used to reference sets of processes, events, and propositions that had appeared earlier in the text, allowing the writer to reason about them further. Professional scientific texts also use demonstratives to establish reference; however they appear to do so sparsely; for example, in a typical science text analyzed by Halliday (1998b), only four pronouns Subjects appeared in seven lengthy paragraphs. More frequently, a demonstrative determiner was used in combination with a technical noun, e.g., "this molecular path." The frequent use of demonstrative pronouns in these results means that the texts built abstraction and complexity; however, they did not do so using an external taxonomy of scientific terms. Instead, they relied on anaphoric reference to meanings construed earlier in the same text. Thus, these texts created a set of concepts that were instantial rather than systemic.

\subsection{Limitations.}

It is not claimed here that writing always contributes to learning; rather writing may or may not lead to learning, depending on the characteristics of the particular writing task, and the writing strategies of the student (e.g., Bangert-Drowns et al., 2004; Klein et al., 2007; Rivard, 2004). An additional limitation arises from the recognition that each genre is defined by its social purpose; the present type of writing task, which is similar to a learning journal, is common in contemporary educational settings. However, the learning journal as a genre differs from most forms of writing, in that it usually has no readership other than the writer and the teacher (here, 
the researcher). Consequently, we would not assume that the linguistics of this science activity would be similar to the linguistics of other kinds of science writing activities.

A third limitation of this research is that the science demonstrations were specifically selected to provide perceptual experiences that challenged students' prior misconceptions. This kind of discrepant experience is characteristic of many classic science demonstrations (e.g., Bobrowsky, 2011, June); however, other types of learning experiences, such as reading and writing from text sources, could result in texts with different linguistic features. A fourth limitation is that the participants in this study were students in a research-intensive university with high admissions standards, so although they had had very limited physics knowledge, they were academically strong in other respects; in this sense, they were not representative of all learners (c.f., Rivard, 2004).

\subsection{Logogenesis, Learning, and Educational Implications.}

Within these limitations, some implications for learning and teaching can be tentatively suggested. The texts in this study showed an incremental process of constructing knowledge; teachers could consider prompting or modeling this for students who are preparing to write learning logs. As students begin writing, they could describe events in congruent terms. In the middle of a text, students could reference these events using nouns or pronouns, and create connections among them; for example, they could use temporal relators to link events that are simultaneous or successive in time. Toward the end of a text, students could reference sets of events, and create causal connections among them, to explain why the phenomenon of interest occurs.

One issue to consider is the degree of formality to be expected in exploratory writing activities. In professional text, the Subject of a clause is frequently a process, event, or 
proposition, metaphorically construed through a technical noun. However, nominal grammar can probably be produced only by those who understand the relevant concepts before they begin writing (Halliday, 1998b, p. 93). Therefore, teachers could accept, and even model, the use of anaphora to iteratively build ideas throughout a text. At the same time, students may use demonstrative pronouns, which taken alone, can be ambiguous. Therefore, it could be useful for the teacher to model the clarification of reference by changing demonstrative pronouns to demonstrative determiners, e.g., "This explanation" or "these events."

Similar considerations apply to the metaphorical use of verbs. Whereas professional science writing frequently uses impersonal relational verbs to construe abstract evidential relationships, these writers used mental verbs to provide personal narratives about changes in their beliefs. These narratives expressed evidential relationships, but congruently grounded them in specific perceptual experiences. This suggests that it could useful for teachers to prompt and model this type of reflective writing about experience. This suggestion is consistent with the findings of a previous meta-analysis, which found that the use of metacognitive writing prompts contributed significantly to learning during writing intensive units of study (Bangert-Drowns et al., 2004).

Another instructional issue arises from the fact that participants in this study frequently used technical terms (e.g., force, density, weight, mass) with meanings that differed from their standard scientific meanings, and were sometimes inconsistent within a given text. For example, when Alexis explained that the air bubbles reduced the mass of the water, the accepted scientific term would instead have been density; additionally, she used the terms mass and density interchangeably. However, we suggest that this kind of usage was not merely wrong. In the context of Alexis' experiment, the concepts of mass and density were related, in the sense that 
for a given volume of liquid, a reduction in mass implied a reduction in density. We suggest that she realized that some attribute of the medium affects the buoyancy of objects immersed in it; she seemed to be responding to the fact that perceptually, this attribute was experienced as something like "heaviness," so she tried out a series of terms from her vocabulary (weight, density, mass) to express this. The inference that she was gaining insight as she wrote is supported by the fact that her predictions about buoyancy in novel situations improved markedly from pretest to post-test. This process, in which individuals use scientific terms to express their experience, gradually bringing their usage in line with accepted meanings, has been reported previously in the research literature (Wickman \& Östman, 2002). This suggests the need for educators to tolerate some initial inaccuracy, and gradually shape students' vocabulary toward more conventional use.

Conversely, some authors have proposed that nominalization "blackboxes" scientific concepts, protecting them from critical analysis, and mystifying readers concerning their meaning (Latour, 1987; Reeves, 2005). The present findings elaborate and complicate this claim in three ways. First, consistent with this claim, each writer showed some blackboxing in the opening sentences of his or her text by using technical nouns in a way that did not actually explain why the events occurred. This suggests that students should be encouraged to move beyond facile explanations by explicitly connecting technical terms to concrete experiences. Second, rather than relying mainly on nominalization to transcategorize processes and propositions, these writers frequently relied on pronouns; this reduced blackboxing because each referent could be retrieved from the preceding text. Thirdly, in the middle and latter parts of these texts, nominalization was used, but it appeared to play a constructive and benign role. Writers used it to topicalize, build upon, and even criticize their initial ideas, e.g., "My answer 
about gravity etc was incorrect" (Patrick). Here, in a (dead) grammatical metaphor, answering, which is a process, was construed using a noun so that it could serve as the Subject of the clause. In this type of instance, nominalization implies the precise opposite of the disappearance of the authorial subject.

\section{Conclusion}

Writing to learn is a particularly revealing context for research on logogenesis. During logogenesis, perceptual experience is incrementally construed to create meaning. In some sense, all writing involves making meaning. However, in writing to learn activities such as this one, the goal is specifically for the students to construct meanings that are, for them, new. This study found that logogenesis in writing to learn in science partially parallels logogenesis in professional scientific text. Writers began with a dynamic construal of experience, and progressed toward a relatively synoptic construal. This involved an iterative process of introducing experiences and ideas, and then transcategorizing and compacting them so that they could serve as the Subjects of subsequent clauses. Students then connected these to other events to form explanatory theories. This logogenetic process paralleled development in two other timeframes: the historical development of scientific texts from the Middle Ages to the modern era; and the ontogenetic development of children as they progress through educational levels (Biber \& Vásquez, 2008; Christie \& Derewianka, 2008; Kopple, 2002; Painter, 1999). This parallel supports the view that the features of scientific text are not merely conventional, but are grounded in the nature of experience and language production.

At the same time, specific differences were found between professional scientific text and writing to learn. Whereas professional text relies on technical nouns to represent processes, events, and propositions, these writers relied heavily on demonstrative pronouns that referred to 
processes, events, and propositions introduced earlier in a given text. This allowed them to construct new knowledge in a way that was scientifically complex and abstract, yet instantial. Similarly, rather than using relational verbs to represent evidential relationships, they created narratives of the changing relationships between their beliefs and perceptual experiences. Based on these results, it is tentatively suggested that teachers could consider prompting or teaching writing practices such as the incremental construal of perceptual experience, the use of nontechnical forms of transcategorization, and the reflective juxtaposition of expectations and experiences. 


\section{References}

Bangert-Drowns, R. L., Hurley, M. M. \& Wilkinson, B. (2004). The effects of school-based writing-to-learn interventions on academic achievement: A meta-analysis. Review of Educational Research, 74, 29-58.

Banks, D. (2005). On the historical origins of nominalized process in scientific text. English for Specific Purposes, 24, 347-357.

Biber, D. \& Vásquez, C. (2008). Writing and speaking. In C. Bazerman (Ed.), Handbook of research on writing: History, society, individual, text (pp. 535-548). New York: Lawrence Erlbaum Associates.

Bobrowsky, M. Lecture-Demonstration Facility, Department of Physics, The University of Maryland. http://www.physics.umd.edu/lecdem/ Retrieved June 28, 2011.

Brown, D. E. (1989). Students' concept of force: the importance of understanding Newton's third law. Physics Education, 24, 353-358.

Christie, F. (1989). Language development in education. In R. Hasan, R. \& J. R. Martin (Eds.), Language development: Learning language, learning culture. Meaning and choice in language; Studies for Michael Halliday. (pp. 152-198). Norwood: Ablex Publishing Company.

Christie, F. (1998). Learning the literacies of primary and secondary schooling. In F. Christie \& R. Misson (Eds.), Literacy and schooling (pp. 47-73). London: Routledge.

Christie, F. \& Derewianka, B. (2008). School discourse: Learning to write across the years of schooling. London: Continuum.

Christie, F., \& Macken-Horarik, M. (2011). Disciplinarity and school Subjects English. In F. Christie \& K. Maton (Eds.), Disciplinarity: Functional linguistic and sociological 
perspectives (pp. 175-196). London: Continuum International Publishing Group.

Coffin, C. (2004). Learning to write history the role of causality. Written Communication, 21, 261-289.

Cronin, B. (2004). Bowling alone together: Academic writing as distributed cognition. Journal of the American Society for Information Science and Technology, 55, 557-560.

Drabick, D. A. G., Weisberg, R., Paul, L., \& Bubier, J. L. (2007). Keeping it short and sweet: Brief, ungraded writing assignments facilitate learning. Teaching of Psychology, 34, 172176.

Donald, M. (2001). A mind so rare. New York: W. W. Norton \& Company.

Emig, J. (1977). Writing as a mode of learning. College Composition and Communication, 28, 122-128.

Fang, Z., \& Schleppegrell, M. J. (2010). Disciplinary literacies across content areas: Supporting secondary reading through functional language analysis. Journal of Adolescent \& Adult Literacy, 53, 587-597.

Galbraith, D. (2009). Writing about what we know: Generating ideas in writing. In R. Beard, D. Myhill, J. Riley, \& M. Nystrand (Eds.), The sage handbook of writing development (pp. 48-64). London, UK: Sage Publication.

Goody, J. \& Watt, I. (1963). The consequences of literacy. Comparative studies in Society and History, 5, 304-345.

Gunel, M., Hand, B., McDermott, M. A. (2009). Writing for different audiences: Effects on highschool students' conceptual understanding of biology. Learning and Instruction, 19, 354367. doi:10.1016/j.learninstruc.2008.07.001 
Halliday, M. A. K. (1997). The grammar of scientific English. In J. J. Webster (Ed.), The language of science: The collected works of M. A. K. Halliday, Vol. 5 (pp. 181-198). London: Continuum. (Reprinted from Grammatica: Studi interlinguistici, by C. T. Torsello, (Ed.), 1997, Padova: Unipress)

Halliday, M. A. K. (1998a). Language and knowledge: The unpacking of text. In J. J. Webster (Ed.), The language of science: The collected works of M. A. K. Halliday, Vol. (pp. 52448). London: Continuum.

Halliday, M. A. K. (1998b). Things and relations: Regrammaticizing experience as technical knowledge. In J. R. Martin \& R. Veel (Eds.), Reading science: Critical and functional perspectives on the discourses of science (pp. 185-235). London: Routledge.

Halliday, M. A. K. (1999). The grammatical construction of scientific knowledge: the framing of the English clause. In J. J. Webster (Ed.), The language of science. The collected works of M. A. K. Halliday, Vol. 5 (pp. 102-134). London: Continuum. (Reprinted from Incommensurability and translation: Kuhnian perspectives on scientific communication and theory change, R. R. Favretti, G. Sandri, \& R. Scazzieri, (Eds.), 1999, Cheltenham: Edward Elgar).

Halliday, M. A. K., \& Matthiessen, C. M. I. M. (1999). Construing experience through meaning: A language-based approach to cognition. London: Continuum.

Halliday, M. A. K., \& Matthiessen, C. M. I. M. (2004). Introduction to functional grammar, $\left(3^{\text {rd }}\right.$ ed.). London, UK: Hodder Education.

Hood, S. (2011). Writing discipline: Comparing inscriptions of knowledge and knowers in academic writing. In F. Christie \& K. Maton (Eds.), Disciplinarity: Functional linguistic 
and sociological perspectives (pp. 106-128). London: Continuum International Publishing Group.

Klein, P. D. (1999). Reopening inquiry into cognitive processes in writing-to-learn. Educational Psychology Review, 11, 203-270.

Klein, P. D. (2004). Constructing scientific explanations through writing. Instructional Science, $32,191-231$.

Klein, P. D., Piacente-Cimini, S. \& Williams, L. A. (2007). The role of writing in learning from analogies. Learning and Instruction, 17, 595-611.

Klein, P. D., \& Yu, A. M. (2013). Best practices in writing to learn. In S. Graham, C. A. MacArthur, J. Fitzgerald (Eds.), Best practices in writing to learn (2nd ed.; pp. 166-189). New York: The Guilford Press.

Kopple, W. J. V. (2002). From the dynamic style to the synoptic style in the Physical Review: Beginnings and 1980. Written Communication, 19, 227-264.

Kurtz, K. J., Miao, C.-H., \& Gentner, D. (2001). Learning by analogical bootstrapping. The Journal of the Learning Sciences, 10, 417-446.

Latour, B. (1987). Science in action: How to follow scientists and engineers through society. Harvard university press.

Macken-Horarik, M. (2002). Something to shoot for: A systemic functional approach to teaching genre in secondary school science. In A. M. Johns (Ed.), Genre in the classroom: Multiple perspectives (pp. 17-42). Mahwah, NJ: Lawrence Erlbaum Associates, Publishers.

Martin, J. R. (1989). Factual writing: Exploring and challenging social reality. Oxford University Press. 
Martin, J. R. (2011). Bridging troubled waters: Interdisciplinarity and what makes it stick. In F. Christie \& K. Maton (Eds.), Disciplinarity: Functional linguistic and sociological perspectives (pp. 35-61). London: Continuum International Publishing Group.

Maton, K. (2011). Theories and things: The semantics of disciplinarity. In F. Christie \& K. Maton (Eds.), Disciplinarity: Functional linguistic and sociological perspectives (pp. 6284). London: Continuum International Publishing Group.

Massoud, L. A., \& Kuipers, J. C. (2008). Objectification and the inscription of knowledge in science classrooms. Linguistics and Education, 19, 211-224.

Nückles, M., Hübner, S., \& Renkl, A. (2009). Enhancing self-regulated learning by writing learning protocols. Learning and Instruction, 19, 259-271.

Oatley, K., \& Djikic, M. (2008). Writing as thinking. Review of General Psychology, 12, 9-27.

Ong, W. J. (1982). Orality and literacy: The technologizing of the word. London: Methuen.

Painter, C. (1999). Learning through language in early childhood. London: Cassell.

Reeves, C. (2005). " I new there was something wrong with that paper": Scientific rhetorical styles and scientific misunderstandings. Technical Communication Quarterly, 14, 267275.

Rivard, L. P. (2004). Are language-based activities in science effective for all students, including low achievers?. Science Education, 88, 420-442.

Schleppegrell, M. J. (2011). Supporting disciplinary learning through language analysis: Developing historical literacy. In F. Christie \& K. Maton (Eds.), Disciplinarity: Functional linguistic and sociological perspectives (pp. 197-216). London: Continuum International Publishing Group. 
She, Hsiao-Ching. (2002). Concepts of a higher hierarchical level require more dual situated learning events for conceptual change: a study of air pressure and buoyancy. International Journal of Science Education, 24, 981-996.

Veel, R. (1997). Learning how to mean—scientifically speaking.: Apprenticeship into scientific discourse in the secondary school. In F. Chrtistie \& J. R. Martin (Eds.), Genre and institutions: Social processes in the workplace and school (pp. 161-195). London: Continuum International Publishing Group. London: Continuum.

Viechnicki, G. B. (2008). Grammatical processes of objectification in a middle school science classroom. Linguistics and Education, 19, 244-264.

Wallace, C. S., Hand, B., \& Prain, V. (2004). Writing and learning in the science classroom. Dordrecht: Kluwer.

Wickman, P.-O. \& Östman, L. (2002). Learning as discourse change: A sociocultural mechanism. Science Education, 86, 601-623.

Wright, L. J. (2008). Learning by doing: The objectification of knowledge across semiotic modalities in middle school chemistry lab activities. Linguistics and Education, 19, 225243.

Yore, L. D., Hand, B. M. \& Prain, V. (2002). Scientists as writers. Science Education, 86, 672692. 
[Insert Appendix One with Figure here]

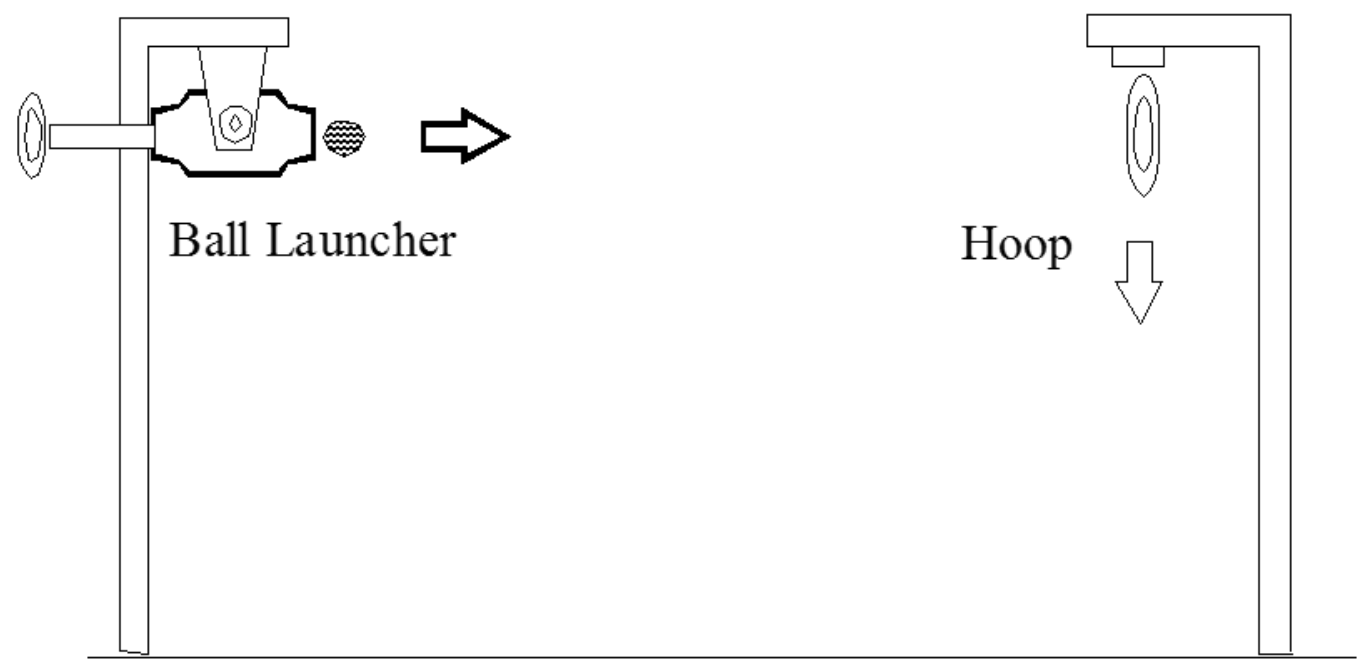


Appendix Two:

Buoyant Force of a Fluid, Illustrative Item from Pretest/ Post-Test

1. Regular soda pop contains sugar, but diet soda pop does not, so the weight of a can of regular soda pop is greater. An egg floats in diet soda pop. In regular pop, the egg will....
(A) float higher than in diet soda pop
(B) float at the same level as in diet soda pop
(C) sink
(D) cannot predict from this information

Why? 